\title{
Molecular

\section{Targeting GSTP1-1 induces JNK activation and leads to apoptosis in cisplatin-sensitive and -resistant human osteosarcoma cell lines $\dagger \dagger$}

\author{
Andrea Sau, ${ }^{a}$ Giuseppe Filomeni, ${ }^{b}$ Silvia Pezzola, ${ }^{a}$ Simona D’Aguanno, ${ }^{c d}$ \\ Francesca Pellizzari Tregno, ${ }^{a}$ Andrea Urbani ${ }^{c d}$ Massimo Serra, ${ }^{e}$ Michela Pasello, ${ }^{e}$ \\ Piero Picci, ${ }^{e}$ Giorgio Federici ${ }^{d f}$ and Anna Maria Caccuri ${ }^{a} a$
}

Received 15th July 2011, Accepted 14th October 2011

DOI: $10.1039 / \mathrm{c} 1 \mathrm{mb05295k}$

The effect of the glutathione transferase P1-1 (GSTP1-1) targeting has been investigated in both sensitive (U-2OS) and cisplatin-resistant (U-2OS/CDDP4 $\mu \mathrm{g}$ ) human osteosarcoma cell lines. Despite the different enzyme's content, inhibition of GSTP1-1 by 6-(7-nitro-2,1,3-benzoxadiazol4-ylthio)hexanol (NBDHEX) causes the activation of c-Jun N-terminal kinase (JNK) and apoptosis in both cell lines. However, different time courses of JNK activation and cell responses are observed. Whereas in the U-2OS/CDDP4 $\mu \mathrm{g}$ cell line drug treatment results in an early increase of caspase activity and secondary necrosis, in the U-2OS cells it mainly causes an early cell cycle arrest followed by apoptosis. In order to elucidate the action mechanism of NBDHEX we performed a proteomic investigation by label-free $\mathrm{nLC}^{-M S^{\mathrm{E}}}$. The high-throughput analysis associated with a bioinformatic tool suggested the involvement of the TNF receptor associated factor (TRAF) family in the cellular response to the drug treatment. We report experimental evidence of the interaction between GSTP1-1 and TRAF2 and we demonstrate that NBDHEX is able to dissociate the GSTP1-1:TRAF2 complex. This restores the TRAF2: ASK1 signaling, thereby leading to the simultaneous and prolonged activation of JNK and p38. These mitogenactivated protein kinases (MAPKs) mediate different effects: JNK is crucial for apoptosis, whereas p38 causes an increase in the p21 level and a concomitant cell cycle arrest. Our study shows that GSTP1-1 plays an important regulatory role in TRAF signaling of osteosarcoma and discloses new features of the action mechanism of NBDHEX that suggest potentially practical consequences of these findings.

\section{Introduction}

The GSTs (EC 2.5.1.18) are a multigene family of isoenzymes involved in the detoxification of endogenous as well as exogenous substances. ${ }^{1}$ In addition, the GST isoenzyme GSTP1-1 is frequently over-expressed in tumor cells and protects them from apoptosis by regulating the MAPK cascades. In fact, Adler et al. ${ }^{2}$ had demonstrated that GSTP1-1 efficiently

${ }^{a}$ Department of Chemical Sciences and Technologies, University of TorVergata, Rome, Italy.E-mail: caccuri@uniroma2.it;

Tel: +390672596204

${ }^{b}$ Department of Biology, University of Tor Vergata, Rome, Italy

${ }^{c}$ Laboratory of Proteomics, IRCCS-Santa Lucia Foundation, Rome,

Italy

${ }^{d}$ Department of Internal Medicine, University of Tor Vergata, Rome, Italy

${ }^{e}$ Laboratory of experimental Oncology, Istituto Ortopedico Rizzoli, IRCCS, Bologna, Italy

${ }^{f}$ Children's Hospital IRCCS “Bambin Gesù”, Rome, Italy

$\dagger$ Presented, in part, at the 6th Annual National Conference of the Italian Proteomics Association held in Turin 21st-24th June 2011.

$\ddagger$ Electronic supplementary information (ESI) available. See DOI: $10.1039 / \mathrm{clmb} 05295 \mathrm{k}$ inhibits the activity of JNK by forming a GSTP1-1:JNK heterocomplex. Furthermore, Wu et al. ${ }^{3}$ have recently shown that GSTP1-1 inhibits TRAF2 in human cervical carcinoma HeLa cells. TRAF2 is an adaptor protein which mediates the signal transduction of different receptors ${ }^{4}$ and it is required for the activation of the apoptosis signal-regulating kinase (ASK1), which in turn activates both mitogen-activated protein kinase (MKK)4/7-JNK and MKK3/4/6-p38 signaling pathways. ${ }^{5}$ Overall, these findings show that GSTP1-1 plays an important regulatory role in both intrinsic and extrinsic signaling pathways, thereby explaining why the elevated expression of this isoenzyme has been implicated in the resistance to apoptosis initiated by a variety of stimuli. We and other authors have recently reported that the level of cisplatin (cis-diaminedichloroplatinum, CDDP) resistance in human osteosarcoma cell lines was mainly related to the increase of protein levels and enzymatic activity of GSTP1-1. ${ }^{6}$ We observed that the strong GSTP1-1 inhibitor 6-(7-nitro-2,1,3benzoxadiazol-4-ylthio)hexanol (NBDHEX) ${ }^{7-9}$ caused a significant cytotoxicity in both sensitive and resistant osteosarcoma cell lines including those with elevated GSTP1-1 protein levels. ${ }^{6}$ 
NBDHEX is a non-GSH-peptidomimetic inhibitor that binds tightly to the H-site of GSTP1-1 and then it is conjugated with GSH leading to the formation of an intermediate $\sigma$-complex. The main driving force that stabilizes the $\sigma$-complex-GSTP1-1 adduct is the interaction between the benzoxadiazole nitro group and a positively charged arginine located at the bottom of the H-site. This interaction is maximal when the $\sigma$-complex is formed and the nitro group acquires a net negative charge. ${ }^{7,8}$ It has been reported that the combination of NBDHEX and CDDP proved to be either additive or synergistic in human osteosarcoma cell lines, resulting in an increased cytotoxicity, particularly in the CDDP-resistant cells. ${ }^{6}$ Therefore, we decided to use the U-2OS cell line and its CDDP-resistant variant, the U-2OS/CDDP4 $\mu \mathrm{g}$ cell line, to detail the NBDHEX action mechanism in human osteosarcoma. NBDHEX is known to cause the release of JNK from the complex with GSTP1-1 and to promote a JNK-mediated apoptosis. ${ }^{9-14}$ Our study confirms this mechanism in human osteosarcoma cell lines and shows that the activation of the MAPK signaling pathway causes different effects. In order to get deeper insights into the NBDHEX action mechanism, we performed a comparative proteomic investigation of the $\mathrm{U}-2 \mathrm{OS}$ untreated cell line and cells treated with the drug by label-free $\mathrm{nLC}-\mathrm{MS}^{\mathrm{E}}$. The subsequent functional pathway analysis suggested the involvement of the TRAF protein family. Finally, we acquired independent evidence of the possible interaction between GSTP1-1 and TRAF2 in osteosarcoma and of the ability of NBDHEX to disrupt this interaction.

\section{Results}

\subsection{NBDHEX induces cell cycle arrest and apoptosis in U-2OS cells}

The exposure of the U-2OS cells to $5 \mu \mathrm{M}$ of NBDHEX (a concentration corresponding to 7-fold the $\mathrm{IC}_{50}$ value) caused an early and persistent inhibition of cell growth, while the untreated cells were in active proliferation (Fig. 1, panel A). Trypan blue staining showed a negligible amount of necrosis in NBDHEX-treated cultures (data not shown) and cell cycle analysis revealed that the inhibition of cell proliferation was a consequence of cycle arrest in the G2/M phase starting at 6 hours after treatment and continuing up to 48 hours (Fig. 1, panel B). At 48 hours of treatment, the occurrence of apoptosis was revealed by the increase of caspase activity and the cleavage of the caspase- 9 and caspase- 3 pro-forms to their active forms (Fig. 2, panels A and B). At this time, nuclear fragmentation and chromatin condensation began to be detected in approximately $15 \%$ of the cell population (Fig. 2, panel C) and this value slightly increased with the incubation time (data not shown). Inhibition of caspase activity, with the general caspase inhibitor, Z-VAD-fmk, completely prevented the occurrence of chromatin fragmentation in the U-2OS cells (Fig. 2, panel D) confirming that the NBDHEX-induced cell death was a caspase-dependent event.

\subsection{NBDHEX induces apoptosis in $\mathrm{U}-2 \mathrm{OS} / \mathrm{CDDP} 4 \mu \mathrm{g}$ cells}

Thereafter, we analyzed the effect of NBDHEX on the U-2OS/ CDDP4 $\mu \mathrm{g}$ cell line, a CDDP resistant variant of U-2OS, that

\section{U-2OS}

A
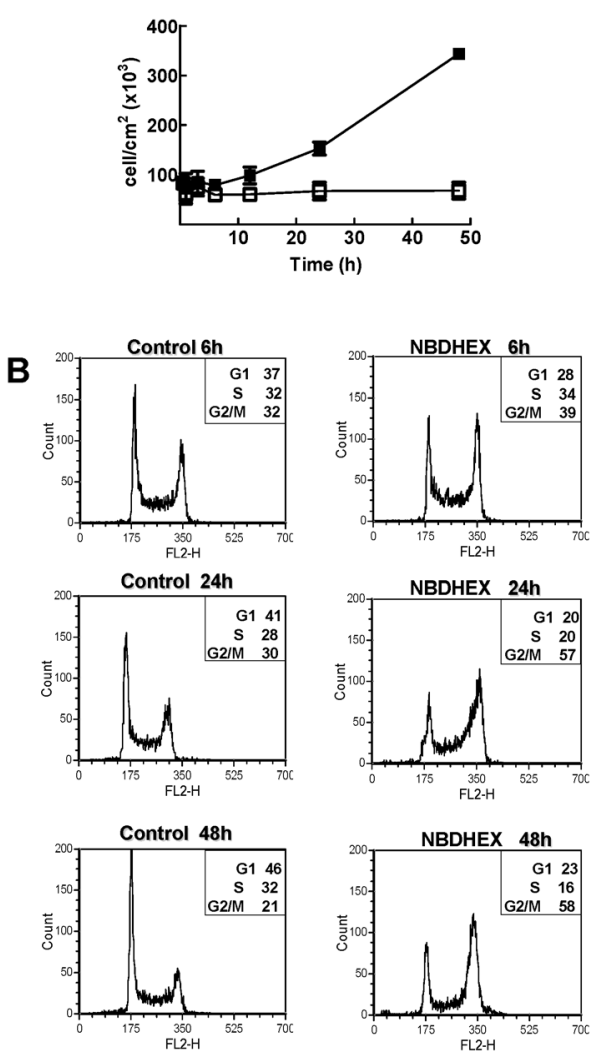

Fig. 1 NBDHEX suppresses cell proliferation in the U-2OS cell line (A) Cell number was determined in the absence ( $\mathbf{\square})$ and in the presence $(\square)$ of $5 \mu \mathrm{M}$ of NBDHEX. Exposure to the drug caused a sustained suppression of cell growth. (B) U-2OS cells, obtained at different times of incubation (6, 24 and 48 hours) with $5 \mu \mathrm{M}$ of NBDHEX, were analyzed by a FACSCalibur instrument. Cell cycle analysis showed an arrest of cell growth in the G2/M phase starting at 6 hours after treatment and continuing up to 48 hours of treatment. The data reported are representative of three independent experiments with similar results.

shows higher GSTP1-1 levels and lower sensitivity to NBDHEX treatment $\left(\mathrm{IC}_{50}=3.9 \mu \mathrm{M}\right)$ compared to the parental cell line $\left(\mathrm{IC}_{50}=0.7 \mu \mathrm{M}\right){ }^{6}{ }^{6} \mathrm{~A} 24$ hour treatment with an equitoxic concentration of NBDHEX $(28 \mu \mathrm{M}$, i.e. 7 fold the $\mathrm{IC}_{50}$ value) caused cell death in approximately $90 \%$ of $\mathrm{U}-2 \mathrm{OS} /$ CDDP4 $\mu$ g population (Fig. 3, panel A) but did not increase the caspase activity. A dose of NBDHEX corresponding to 2.5 -fold the $\mathrm{IC}_{50}$ value $(10 \mu \mathrm{M})$ caused $50 \%$ of cell death at 24 hours, and a time-dependent increase in caspase activity (Fig. 3, panel A). Subsequent experiments on U-2OS/CDDP4 $\mu \mathrm{g}$ cells were then conducted using a drug concentration of $10 \mu \mathrm{M}$. Under these conditions, the Hoechst staining did not show nuclear fragmentation, which is a typical morphological feature of apoptosis (data not shown). Therefore, to confirm that this cell death was a consequence of an apoptotic process, we performed a cytofluorimetric analysis after 24 hours of treatment. The distribution of Annexin V+/PI-, Annexin $\mathrm{V}+/ \mathrm{PI}+$ and Annexin $\mathrm{V}-/ \mathrm{PI}+$ cell sub-fractions suggested that the death recorded for the U-2OS/CDDP4 $\mu \mathrm{g}$ cell line was essentially a secondary necrosis that followed apoptosis 


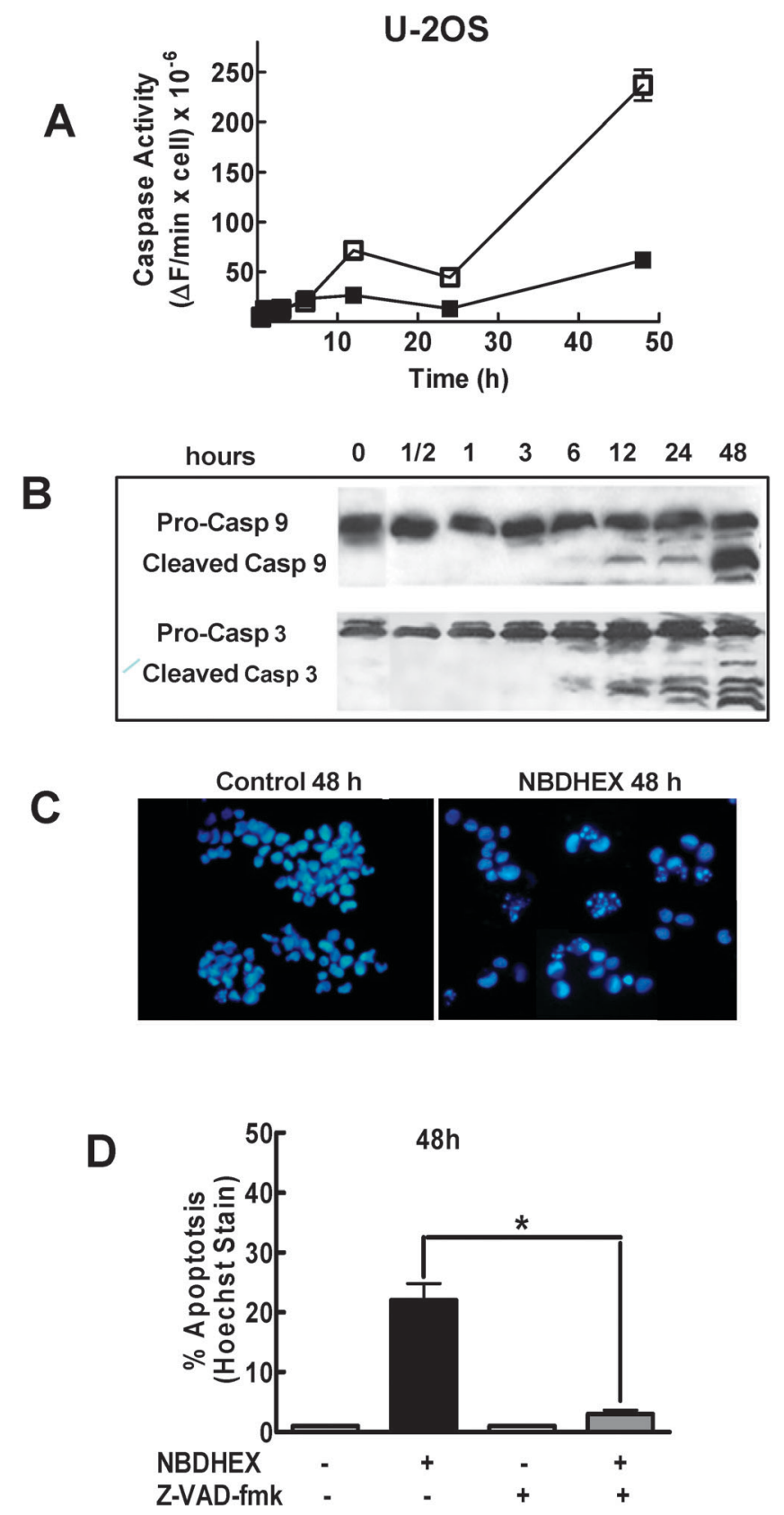

Fig. 2 NBDHEX induces apoptosis in the U-2OS cell line. (A) The kinetics of caspase activation was measured on U-2OS cells incubated in the absence ( $\square$ ) and in the presence ( $\square$ ) of $5 \mu \mathrm{M}$ of NBDHEX. (B) The caspase activation trend was confirmed by the cleavage of procaspase-9 and procaspase-3 to active caspases, determined by immunoblotting. (C) Apoptosis was determined by fluorescence microscopy after nuclear staining with the DNA-specific dye Hoechst 33 342. After 48 hours of treatment, approximately $15 \%$ of apoptotic nuclei were detected. (D) The pancaspase inhibitor Z-VAD-fmk $(40 \mu \mathrm{M})$ completely prevented chromatin fragmentation in U-2OS treated with $5 \mu \mathrm{M}$ NBDHEX for 48 hours.

(Fig. 3, panel B). Indeed, the NBDHEX-induced cell death was a caspase-dependent event: inhibition of caspase activity, with the general caspase inhibitor Z-VAD-fmk, caused a strong reduction of the degree of trypan blue positive cells (Fig. 3, panel C).

\subsection{NBDHEX activates the JNK signaling pathway}

The activation of JNK is an early hallmark during apoptosis triggered by NBDHEX. ${ }^{9}$ We therefore analyzed the changes in the phosphorylation status of this kinase in both U-2OS and
$\mathrm{U}-2 \mathrm{OS} / \mathrm{CDDP} 4 \mu \mathrm{g}$ cell lines. As a result, a prolonged profile of activation was detected for JNK in both cell lines, starting after 30-60 minutes of treatment and persisting for at least 24 hours (Fig. 4, panel A). However, the time courses of activation were quite different in the sensitive and resistant cell lines: a rapid and strong increase of the P-JNK was detected in the U-2OS/CDDP4 $\mu \mathrm{g}$ cells as early as 60 minutes after treatment, while a gradual increase of P-JNK was observed in the U-2OS cell line. To substantiate the role of JNK, we determined the events triggered by NBDHEX in both U-2OS and U-2OS/CDDP4 $\mu \mathrm{g}$ cell lines pre-treated with the JNK 


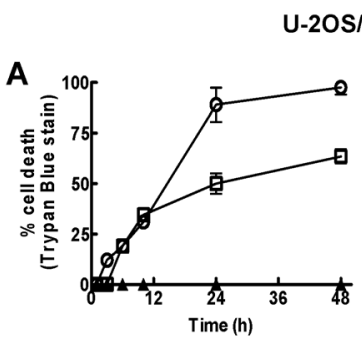

$\mathrm{U}-20 \mathrm{~S} / \mathrm{CDDP} 4 \mu \mathrm{g}$

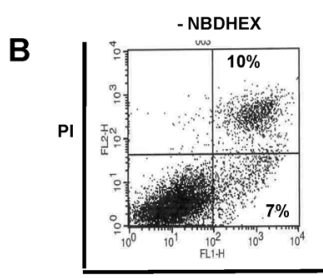

$24 \mathrm{~h}$
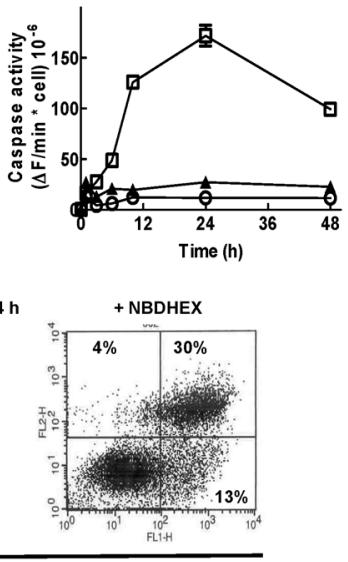

Annexin V

C

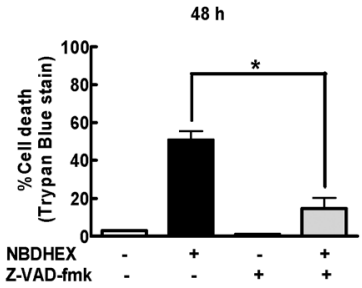

Fig. 3 NBDHEX induces apoptosis in the U-2OS/CDDP4 $\mu \mathrm{g}$ cell line. (A) Time courses of cell death and caspase activation in U-2OS/ CDDP4 $\mu \mathrm{g}$ cells untreated $(\mathbf{\Delta})$ and treated with either $28 \mu \mathrm{M}(\mathrm{O})$ or $10 \mu \mathrm{M}(\square)$ of NBDHEX. (B) Cytofluorimetric analysis of U-2OS/ CDDP4 $\mu \mathrm{g}$ cells treated for 24 hours with $10 \mu \mathrm{M}$ of NBDHEX. The distribution of Annexin V+/PI-, Annexin V+/PI + and Annexin $\mathrm{V}-/ \mathrm{PI}+$ cell sub-fractions suggests that the death recorded was essentially a secondary necrosis that followed apoptosis. (C) The protective effect of Z-VAD-fmk $(40 \mu \mathrm{M})$ was assayed in the U-2OS/ CDDP4 $\mu \mathrm{g}$ cell line treated with $10 \mu \mathrm{M}$ NBDHEX for 48 hours; inhibition of caspase activity strongly reduced cell death in U-2OS/ CDDP4 $\mu \mathrm{g}$ cells.

inhibitor SP600125. Inhibition of JNK caused a significant reduction of caspase activity (approximately 60\% after 48 hours) while it did not affect the degree of G2/M arrest in the U-2OS cell line (Fig. 4, panel B). Moreover, SP600125 caused a considerable decrease of cell death (approximately $50 \%$ after 24 hours) in the NBDHEX-treated U-2OS/CDDP4 $\mu \mathrm{g}$ cell line (Fig. 4, panel B). These results confirm that the JNK pathway activation is the crucial event that mediates the NBDHEX-induced apoptosis. However, JNK is not responsible for the cytostatic effect of NBDHEX in the U-2OS cell line.

\section{4 p38 mediates cell cycle arrest in U-2OS cells}

Several observations have been published that point to a critical role for the p38 MAPK in the G2/M checkpoint. Pharmacological inhibition of p38, as well as inducible expression of a dominant negative p38 mutant, results in abrogation of this checkpoint and in an enhancement of apoptosis. ${ }^{15,16}$ Activation of p38 was detected in the U-2OS cells treated with NBDHEX (Fig. 4, panel C). Moreover, inhibition of p38 by SB203580 caused a significant decrease of cell cycle arrest in the G2/M phase and an increase of caspase activity (Fig. 4, panel D). These results indicate that, unlike JNK, p38 activation promotes the U-2OS cells' survival in response to NBDHEX.

\subsection{TRAF2 is a putative target of NBDHEX in U-2OS cells}

To better understand the mechanisms of cell cycle arrest and apoptosis triggered by NBDHEX in U-2OS cells, we compared the proteome of U-2OS cells exposed to the drug for 24 hours to the proteome of untreated cells. Total protein extracts were analyzed by a shotgun proteomic approach without the use of isotope labelling. Prior relative quantitation, experimental reproducibility was evaluated (Fig. 5). When EMRTs, list of paired peptide exact masses and retention time, of two injections of the same condition were compared, the experimental points are distributed along a diagonal line (panels A and E). This result is an evidence of good data reproducibility since it is not far from the ideal condition in which binary comparisons would yield a perfect 45 degree diagonal intersecting through zero. Moreover for both replicate conditions the distribution of mass error was under $15 \mathrm{ppm}$ with the greater part of peptide species under 4 (panels $\mathrm{B}$ and $\mathrm{F}$ ), the retention time coefficient of variation expressed as percentage ( $\% \mathrm{CV}$ RT) was under $4 \%$ with the greater part of peptide species under 2 (panels $\mathrm{C}$ and $\mathrm{G}$ ) and the intensity coefficient of variation expressed as percentage (\% CV intensity) has a Gaussian distribution with all values under $4.5 \%$ (panels $\mathrm{D}$ and $\mathrm{H}$ ). After quality assessment EMRTs table and protein table were generated. A total of 87640 EMRTs and 225 proteins were qualitatively identified across both conditions. Quantitative analysis was performed after EMRTs and protein normalization by applying the filtering criteria described in the "Experimental" section. Relative quantitative analysis revealed a total of 33 differentially expressed proteins between the two conditions (see Table 1; Tables $1 \mathrm{~S}$ and $2 \mathrm{~S}, \mathrm{ESI} \doteqdot$ ). The significant modulated proteins were classified by their molecular functions using the PANTHER Classification System (http://pantherdb.org) (Fig. 6). Most part of differentially expressed proteins had structural molecular activity $(35.9 \%)$, catalytic activity $(23.1 \%)$, and binding $(20 \%)$, while translation regulation activity $(7.7 \%)$, ion channel activity $(5.1 \%)$, transporter, antioxidant and receptor activities $(2.6 \%)$ were less represented. In order to highlight the possible key candidates responsible for the cellular response to NBDHEX, we performed an unsupervised bioinformatic analysis using the proteomic dataset of modulated proteins. The complete list of modulated proteins was loaded into Ingenuity Pathway Analysis software (IPA) and analysis was performed without any pre-established criteria of inclusion or exclusion. Data investigation revealed a muddled association of interactions among identified proteins and their direct or indirect interactors. Independently analyzing the main nodes of the network, we found that the TRAF family was joined with 13 modulated proteins identified by a shotgun approach with a significant $p$-value $\left(p=2.18 \times 10^{-5}-4.11 \times 10^{-2}\right)($ Fig. 7 , panel A). This analysis was based on the following data: TRAF3 was found joined with microtubules in HeLa cells when it was co-expressed with MIP-T3; ${ }^{17}$ Tubulin isoforms (TUBBs), HSP70s (HSPA 1L and HSPA9) and VCP were identified among TRAF interactors, in a physical and functional map of 


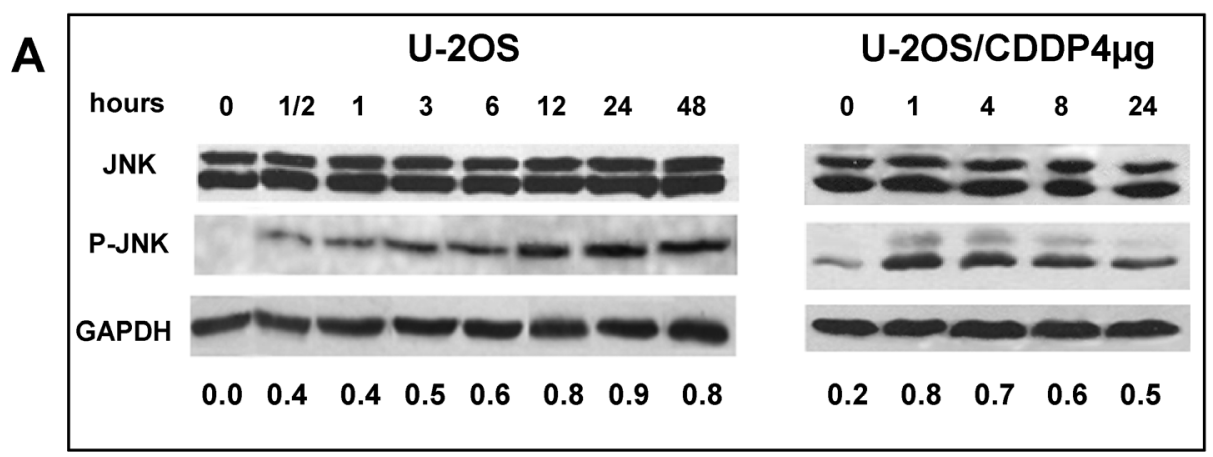

B U-2OS

\section{U-2OS/CDDP4 $\mu g$}
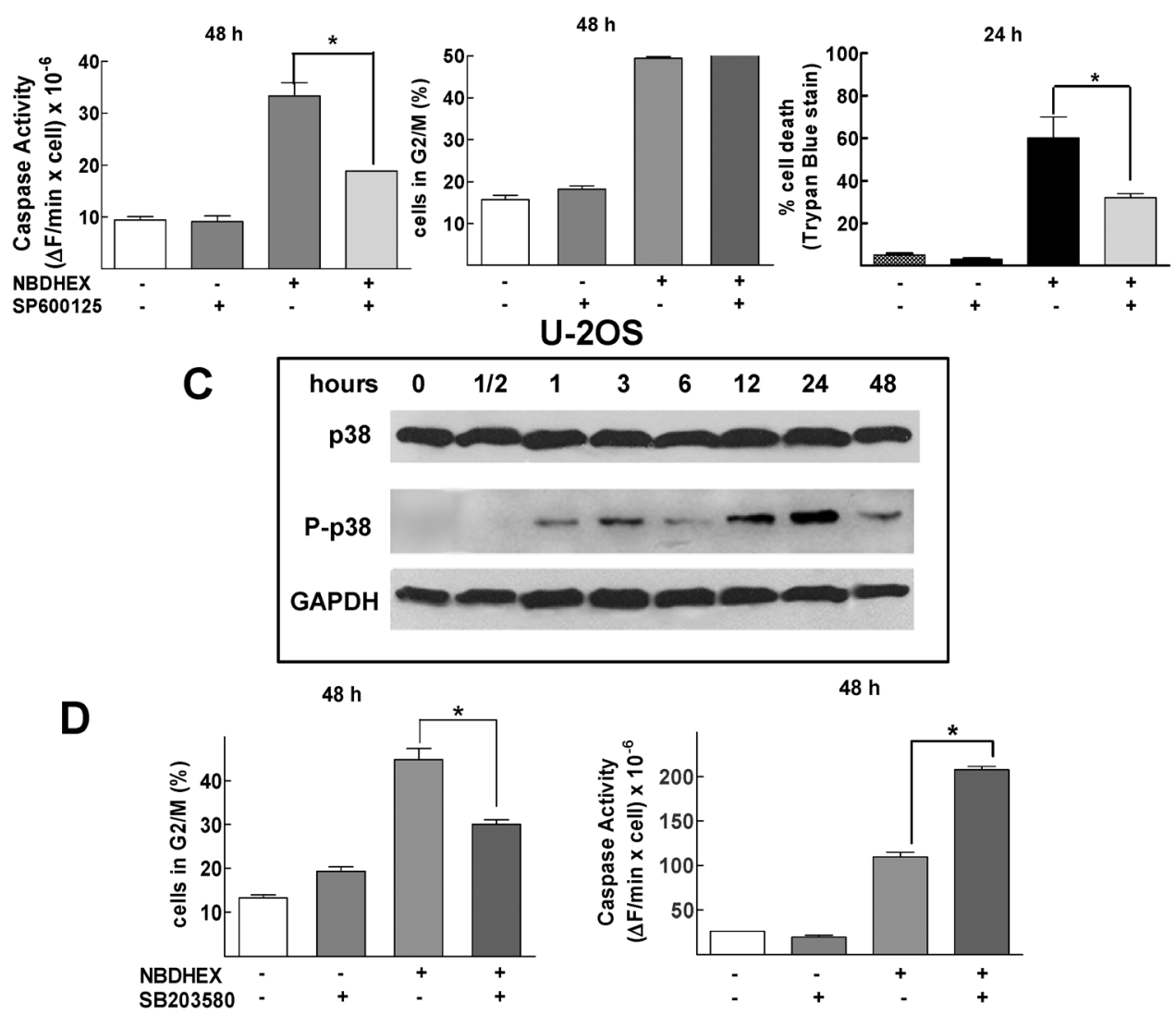

Fig. 4 NBDHEX activates the MAPK signaling pathways. (A) Western blotting analysis of U-2OS cells treated with $5 \mu$ M of NBDHEX shows a gradual increase of the phosphorylated form of JNK. Conversely, a rapid activation of JNK is observed in U-2OS/CDDP4 $\mu \mathrm{g}$ cells treated with $10 \mu \mathrm{M}$ of NBDHEX. Numbers under the bands represent the densitometric values of the P-JNK bands, expressed relative to the loading control GAPDH. (B) The effects of the JNK inhibitor SP600125 were analyzed in U-2OS and U-2OS/CDDP4 $\mu$ g cells treated with NBDHEX for 48 and 24 hours respectively. Inhibition of JNK caused a considerable decrease of caspase activity and of trypan blue positive cells in U-2OS and U-2OS/CDDP4 $\mu \mathrm{g}$ cell lines, respectively. However, SP600125 did not revert cell cycle arrest in U-2OS cells. (C) A rapid phospho-activation of p38 was observed in U-2OS cells treated with $5 \mu \mathrm{M}$ of NBDHEX. (D) Cell cycle progression and apoptosis were analyzed in U-2OS cells treated with $5 \mu \mathrm{M}$ of NBDHEX in the presence of the p38 inhibitor SB203580. Inhibition of p38 caused a decrease of the cell population in the G2/M phase and an increase of caspase activity.

the human TNF-alpha/NF-kappa B signal transduction pathway; ${ }^{18}$ Hsp70 was reported to interact with TRAF6 and to inhibit ubiquitination of this protein by preventing LPSinduced NF-kappa B activation; ${ }^{19}$ PAICS, PPIB, RPS3A and VCP resulted associated to TRAF6 in a large-scale mapping of human protein-protein interactions, ${ }^{20}$ Dai and colleagues reported that HSP70 over-expression in human colon cancer cells can inhibit $\mathrm{TNF} \alpha$-induced $\mathrm{NF} \kappa \mathrm{B}$ activation but promote $\mathrm{TNF} \alpha$-induced activation of JNK through interaction with
TRAF2. ${ }^{21}$ Since TRAF2 has been reported to interact directly with GSTP1-1 ${ }^{3}$ we focused on TRAF2 to elucidate its involvement in apoptosis induction after NBDHEX treatment.

\subsection{NBDHEX affects the GSTP1-1 : TRAF2 complex stability}

We wondered whether or not GSTP1-1 could bind to TRAF2 in the U-2OS cells and whether the NBDHEX treatment could affect this interaction. Lysates of cells treated with $5 \mu \mathrm{M}$ 

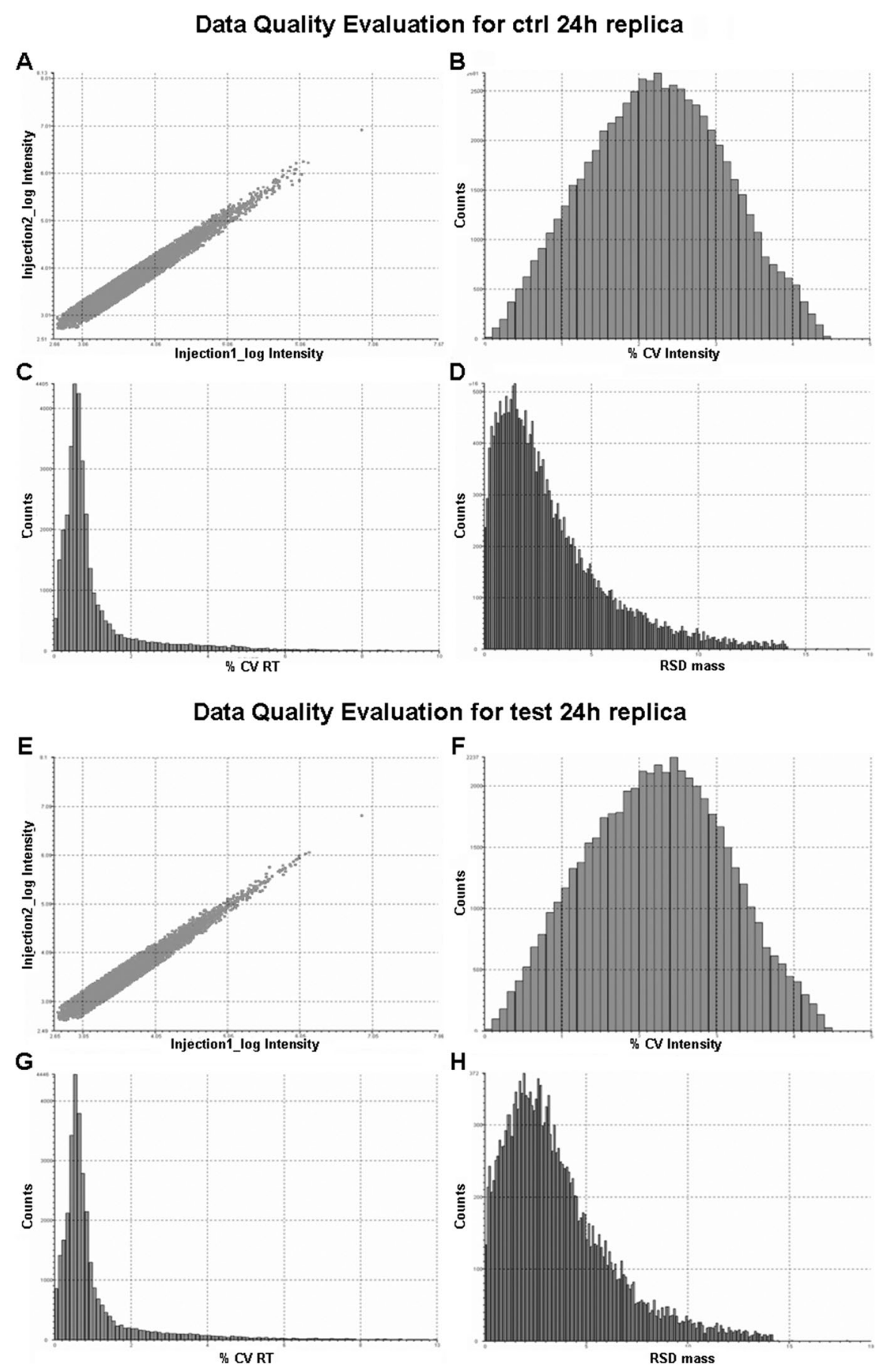

Fig. 5 nLC-MS ${ }^{\mathrm{E}}$ data quality evaluation. Analytical reproducibility assessment in control (not treated) and treated (test) cell lines. The quality of replica was confirmed by binary comparisons in which experimental points of two runs of the same conditions are distributed along a diagonal line with an inclination of about 45 -degree (A, E). Bar chart showing intensity coefficient of variation (\% CV intensity) (B, F), retention time coefficient of variation $(\% \mathrm{CV}$ RT) $(\mathrm{C}, \mathrm{G})$ and mass precision $(\mathrm{D}, \mathrm{H})$ reported for EMRTs of control and treated cell lines.

NBDHEX were immunoprecipitated using the anti-GSTP1-1 antibody. The results of immunoblotting analysis, using the antiTRAF2 antibody, showed TRAF2 associated with GSTP1-1 in the U-2OS cells (Fig. 7, panel B). Notably, the amount of TRAF2 that co-immunoprecipitated with GSTP1-1 rapidly decreased after only 30 minutes of treatment with NBDHEX. Simultaneously, the quantity of free TRAF2 strongly increased in the supernatant fraction during the treatment (Fig. 7, panel B).
These data indicate that NBDHEX triggers the dissociation of GSTP1-1 from the GSTP1-1 : TRAF2 complex.

\subsection{NBDHEX activates the MKK4 signaling pathway}

The release of TRAF2 is known to induce the activation of the MAPK signaling pathways; we therefore analyzed the changes in the phosphorylation status of MKK4, which is a downstream 
Table 1 List of proteins differentially expressed in ctrl $24 \mathrm{~h}$ and test $24 \mathrm{~h}$

\begin{tabular}{|c|c|c|c|c|}
\hline Accession SWISSProt & Protein description & Score PLGS & Ctrl : test ratio ${ }^{a}$ & $\mathrm{SD}^{b}$ \\
\hline \multicolumn{5}{|c|}{ Proteins up-regulated in test } \\
\hline P06576 & ATP synthase subunit beta, mitochondrial precursor & 256 & test & \\
\hline P23284 & Peptidyl-prolyl cis-trans isomerase B precursor & 167 & test & \\
\hline Q13162 & Peroxiredoxin-4 & 118 & test & \\
\hline P38646 & Stress- 70 protein, mitochondrial precursor & 466 & test & \\
\hline P55072 & Transitional endoplasmic reticulum ATPase (VCP) & 528 & test & \\
\hline P08107 & Heat shock $70 \mathrm{kDa}$ protein 1 & 625 & -0.59 & 0.12 \\
\hline P17066 & Heat shock $70 \mathrm{kDa}$ protein 6 & 884 & -0.59 & 0.11 \\
\hline P34931 & Heat shock $70 \mathrm{kDa}$ protein 1 -like & 794 & -0.54 & 0.12 \\
\hline \multicolumn{5}{|c|}{ Proteins up-regulated in ctrl } \\
\hline P68133 & Actin, alpha & 755 & 0.50 & 0.04 \\
\hline P08865 & $40 \mathrm{~S}$ ribosomal protein $\mathrm{SA}$ & 345 & 0.51 & 0.18 \\
\hline Q9BQE3 & Tubulin alpha- 6 chain & 1338 & 0.51 & 0.04 \\
\hline Q13748 & Tubulin alpha-2 chain & 1030 & 0.52 & 0.06 \\
\hline P68363 & Tubulin alpha-ubiquitous chain & 1391 & 0.52 & 0.07 \\
\hline P26641 & Elongation factor 1 -gamma & 322 & 0.54 & 0.20 \\
\hline Q71U36 & Tubulin alpha-3 chain & 1212 & 0.54 & 0.05 \\
\hline P68104 & Elongation factor 1 -alpha 1 & 322 & 0.56 & 0.08 \\
\hline P06454 & Prothymosin alpha & 371 & 0.56 & 0.18 \\
\hline P07355 & Annexin A2 & 854 & 0.60 & 0.06 \\
\hline P12814 & Alpha-actinin-1 & 930 & 0.62 & 0.13 \\
\hline Q13509 & Tubulin beta- 3 chain & 511 & 0.65 & 0.15 \\
\hline P61978 & Heterogeneous nuclear ribonucleoprotein $\mathrm{K}$ & 303 & 0.66 & 0.18 \\
\hline Q13885 & Tubulin beta- $2 \mathrm{~A}$ chain & 606 & 0.66 & 0.10 \\
\hline Q9BVA1 & Tubulin beta-2B chain & 632 & 0.66 & 0.11 \\
\hline P04350 & Tubulin beta- 4 chain & 647 & 0.70 & 0.08 \\
\hline P07437 & Tubulin beta chain & 901 & 0.71 & 0.07 \\
\hline P68371 & Tubulin beta- $2 \mathrm{C}$ chain & 638 & 0.72 & 0.09 \\
\hline P22234 & Multifunctional protein ADE2 (PAICS) & 635 & 0.74 & 0.13 \\
\hline Q9BUF5 & Tubulin beta- 6 chain & 412 & 0.75 & 0.19 \\
\hline P00338 & L-Lactate dehydrogenase A chain & 538 & 0.79 & 0.15 \\
\hline Q15029 & $116 \mathrm{kDa}$ U5 small nuclear ribonucleoprotein component & 447 & ctrl & \\
\hline P61247 & $40 \mathrm{~S}$ ribosomal protein $\mathrm{S} 3 \mathrm{a}$ & 348 & ctrl & \\
\hline P62081 & $40 \mathrm{~S}$ ribosomal protein $\mathrm{S} 7$ & 159 & ctrl & \\
\hline Q16352 & Alpha-internexin & 357 & ctrl & \\
\hline
\end{tabular}

kinase of TRAF2 and directly phosphorylates and activates both JNK and the closely related p38 MAPK.

Treatment with $5 \mu \mathrm{M}$ of NBDHEX elicited a prolonged activation of MKK4 (Fig. 7, panel C), in accordance with the profile of activation detected for JNK and p38 in this cell line.

\subsection{Cell cycle arrest and apoptosis are transcription-dependent events in U-2OS cells}

NBDHEX induced c-Jun and ATF-2 phospho-activation as early as 30-60 minutes after treatment (Fig. 8, panel A). These transcription factors are the key components of activating protein-1 (AP-1) and they are involved in the transcriptional regulation of many target genes in response to the activation of JNK and p38. We therefore investigated the necessity of protein synthesis in the events triggered by NBDHEX. Pre-treatment of the U-2OS with the protein synthesis inhibitor cycloheximide $(36 \mu \mathrm{M})$ completely reverted the G2/M arrest. Moreover, inhibition of protein synthesis strongly reduced the NBDHEX-induced apoptosis (Fig. 8, panel B). In fact, caspase activity decreased to approximately $50 \%$ after 48 hours of treatment with NBDHEX and the degree of chromatin condensation and fragmentation was comparable to that observed in the control cells incubated with cycloheximide alone (data not shown). This evidence suggests that cell cycle arrest and apoptosis are primarily the consequence of the early activation of specific transcription factors. Indeed, an incubation period of 3 hours with NBDHEX was sufficient to induce the G2/M arrest and apoptosis. On the other hand, one hour incubation with NBDHEX was not sufficient to induce G2/M arrest (Fig. 8, panel D) and caused only a slight increase in caspase activity (Fig. 8, panel C). Furthermore, after 3 hours of incubation with NBDHEX, the degree of both G2/M arrest (Fig. 8, panel D) and caspase activity (Fig. 8, panel C) was comparable to that observed after 48 hours of continuous exposure.

\section{9 p21 regulates cell cycle arrest in response to NBDHEX}

A functional relationship between p21, G2/M arrest and apoptosis sensitivity has been previously demonstrated. Wendt et al. ${ }^{22}$ have demonstrated that $\mathrm{G} 2$ arrest and the induction of apoptosis are two parallel processes directed by the level of p21. Therefore, we assessed whether or not this cell-cycle regulator was modulated by NBDHEX. An increase of the base level of p21 was detectable in U-2OS cells after 3 hours of treatment with NBDHEX and remained at elevated levels for 24 hours (Fig. 9, panel A). After this time, a decrease of p21 levels was observed, which was likely the consequence of a caspase-3-mediated cleavage. Pre-treatment of the U-2OS with 
Molecular function classification by PANTHER

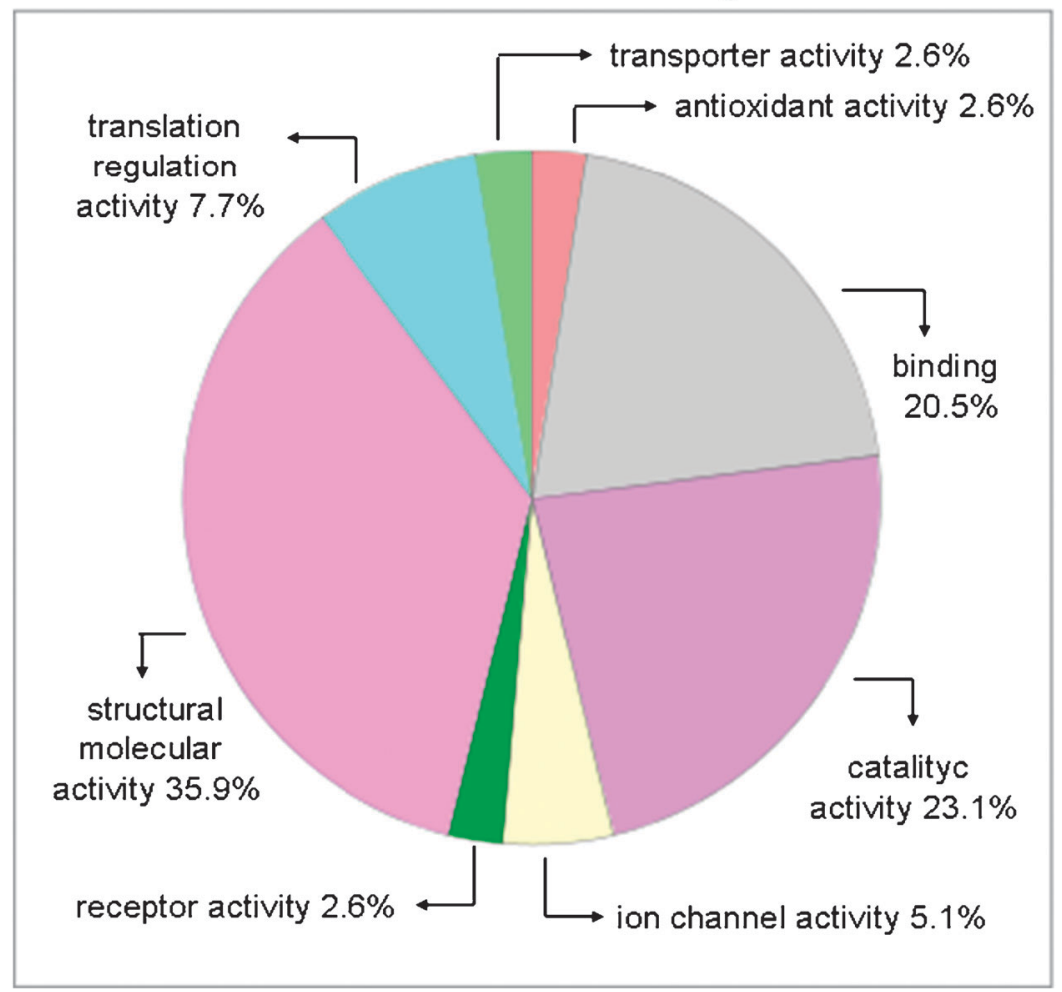

Fig. 6 Protein classification. The differentially expressed proteins, between the NBDHEX-treated and untreated U-2OS cells, were classified by their molecular functions using the PANTHER Classification System.

either cycloheximide $(36 \mu \mathrm{M})$ or SB203580 $(10 \mu \mathrm{M})$ prevented the increase of p21 (Fig. 9, panel B), suggesting that the accumulation of $\mathrm{p} 21$ is a consequence of transcription-dependent events likely mediated by $\mathrm{p} 38$. The central role played by $\mathrm{p} 21$ was confirmed by the effect of caffeine on the U-2OS cell response to NBDHEX. Previous observations ${ }^{22}$ have shown that suppression of p21 expression by caffeine abrogates G2 arrest and allows the induction of apoptosis in MCF-7 cells. Indeed, we observed that caffeine $(2 \mathrm{mM})$, although not toxic when administered alone, inhibited p21 expression (Fig. 9, panel B) and caused an increase in both apoptotic nuclei and caspase activity (Fig. 9, panel C) when used in combination with NBDHEX.

\section{Discussion}

We have recently demonstrated that GSTP1-1 contributes to osteosarcoma chemoresistance and that targeting GSTP1-1 with the GST inhibitor NBDHEX may represent a new therapeutic strategy to be considered in association with conventional treatments in osteosarcoma patients poorly responding to standard chemotherapy. ${ }^{6}$ However, the biological mechanisms involved in NBDHEX activity in human osteosarcoma cells have not been extensively elucidated. Our present findings show that NBDHEX induces an early apoptosis in the cisplatin-resistant U-2OS/CDDP4 $\mu$ g cell line, while it mainly causes cell cycle arrest and a late apoptosis in its parental, drug-sensitive U-2OS cell line. This different response to NBDHEX likely reflects the different time courses of JNK activation observed in these osteosarcoma cell lines. The cell cycle arrest, observed in the parental cell line, may be favoured by the initial low level of JNK activation, while the early apoptosis, observed in the CDDP resistant variant, may be a consequence of the rapid and sustained activation of this kinase. Our findings are consistent with previous works showing that the cellular response to JNK signalling may depend on both the strength and the duration of the signal. ${ }^{23,24}$ However, it is important to consider that, despite the differences observed between U-2OS and U-2OS/CDDP4 $\mu \mathrm{g}$ (which are likely due to the changes acquired by the cisplatin-resistant variant compared to the parental cells), NBDHEX showed an apoptosis induction activity in both cell lines. In turn, this result points out that the U-2OS/CDDP4 $\mu$ g cell line, selected to be resistant to high concentrations of CDDP, is strongly dependent on GSTP1-1, i.e. the neutralization of this enzyme by NBDHEX causes a strong induction of cell death. Thereafter, we decided to identify the key players involved in the molecular mechanisms triggered by NBDHEX in the sensitive U-2OS cell line. For this purpose we followed a proteomic approach associated with an in silico evaluation of cellular pathway activation after drug treatment. This high-throughput study suggested that the TRAF protein family could be implicated in the U-2OS cells' response to NBDHEX. Based on the finding that a member of the TRAF protein family, TRAF2, is physically associated with GSTP1-1 in mammalian cells, ${ }^{3}$ we speculated that GSTP1-1 could interact with TRAF2 in the U-2OS cells and that NBDHEX may disrupt this interaction. In fact, the crystal structure of GSTP1-1 in complex with NBDHEX and $\mathrm{GSH}^{8}$ shows these molecules located within close proximity to 

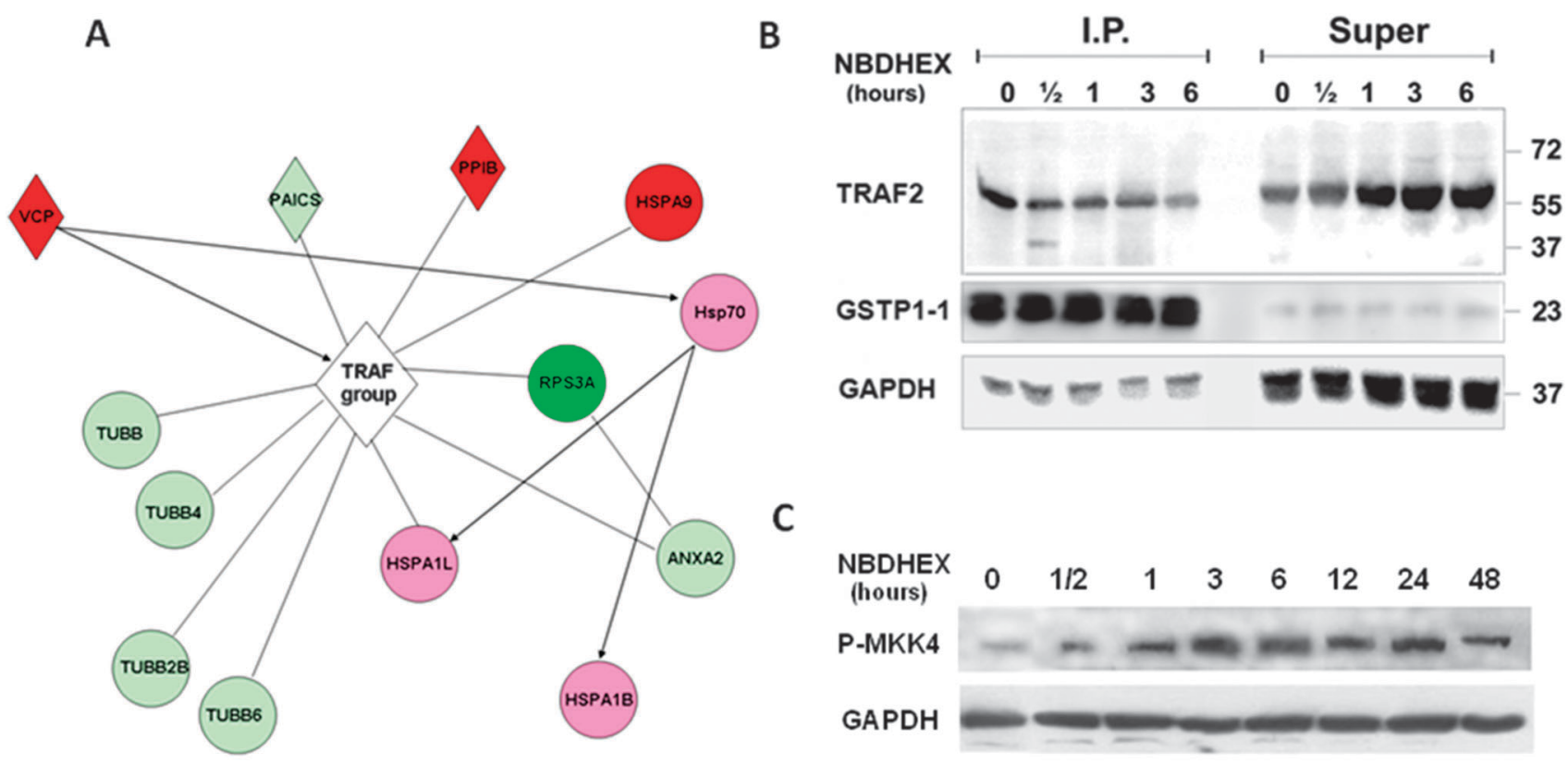

C

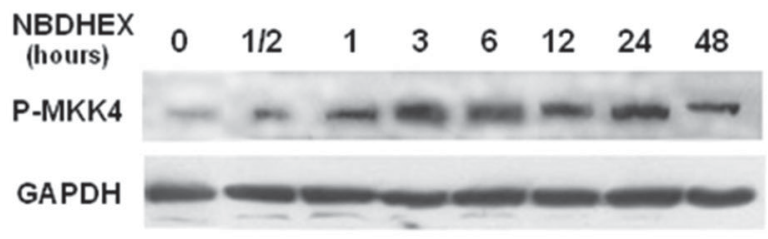

Fig. 7 TRAF2 is a target of NBDHEX. (A) A shotgun proteomic approach was utilized to compare the proteome of U-2OS cells exposed to $5 \mu \mathrm{M}$ of NBDHEX for 24 hours to the proteome of untreated cells. An unsupervised bioinformatic analysis revealed that 13 proteins, differentially expressed in control cells versus treated cells, were associated to TRAF. The image shows proteins identified by the shotgun proteomic approach in the present study (red colour scale: proteins up-regulated in treated cells; green colour scale: proteins up-regulated in untreated cells). Solid lines indicate direct protein-protein interactions. Solid arrow lines indicate proteins acting upon other proteins at an expression level. Abbreviation used: VCP, Transitional endoplasmic reticulum ATPase; PPIB, Peptidyl-prolyl cis-trans isomerase; HSPA9, Stress-70 protein mitochondrial; Hsp70, Heat shock $70 \mathrm{kDa}$ protein; HSPA1L, Heat shock $70 \mathrm{kDa}$ protein 1-like; HSPA1B, Heat shock $70 \mathrm{kDa}$ protein 1; ANXA2, Annexin A2; PAICS, Multifunctional protein ADE2; RPS3A, 40 S ribosomal protein S3a; TUBB, Tubulin beta chain; TUBB4, Tubulin beta-4 chain; TUBB2B, Tubulin beta-2B chain; TUBB6, Tubulin beta- 6 chain. (B) Immunoprecipitation analysis shows TRAF2 associated with GSTP1-1 in the untreated U-2OS cells. The NBDHEX treatment causes a decrease of TRAF2 in the immunoprecipitated (bound to GSTP1-1) and an increase of TRAF2 in the non-immunoprecipitated (Super) fraction. GSTP1-1 and GAPDH were utilized as loading and purity controls. (C) Western blotting analysis of $\mathrm{U}-2 \mathrm{OS}$ treated with $5 \mu \mathrm{M}$ of NBDHEX shows a rapid and sustained activation of MKK4 with respect to untreated control cells.

the TRAF2-binding motif identified by $\mathrm{Wu}$ and colleagues. ${ }^{3}$ NBDHEX establishes several hydrophobic interactions with residues shaping the active site and among them with Trp-38 and Gln-39, which constitute part of the TRAF2-binding site. Successively, we confirmed, by immunoprecipitation analysis, our hypothesis. We provided evidence that NBDHEX treatment may cause a conformational change of GSTP1-1 regions essential for the interaction with TRAF2, and also cause the release of TRAF2 in the cytoplasm. This event leads to the simultaneous and prolonged activation of $\mathrm{JNK}$ and p38 and to the phosphorylation of transcription factors such as c-Jun and ATF2. The transcriptional-dependent events started very early and an incubation period of 1-3 hours with NBDHEX was sufficient to irreversibly commit the U-2OS cells to G2/M arrest and apoptosis. These events were mediated by different MAP kinases: JNK signaling was required for the initiation of the programmed cell death, in accordance with several lines of evidence demonstrating that the increase of JNK/ c-Jun activity exerts a central role in the induction of apoptosis in osteosarcoma. ${ }^{25,26}$ Conversely, p38 signaling, associated with upregulation of p21, caused G2/M arrest and delayed apoptosis. Interestingly, when caffeine was combined with NBDHEX, the efficacy of this drug increased markedly. Caffeine inhibited p21 expression ${ }^{22}$ and overcame the cell cycle checkpoints thus sensitizing osteosarcoma cells to NBDHEX.

\section{Conclusions}

Our data suggest that, in human osteosarcoma cells, GSTP1-1 is able to interfere with the MAPK pathway not only at the JNK level, but also at the TRAF2 level by blocking the upstream signal transduction that leads to JNK and p38 phosphorylation. TRAF2 is an important signal transducer for the wide range of TNF receptor superfamily members. ${ }^{4}$ The release of TRAF2 in the cytoplasm leads to the activation of MAPKs that mediate opposite effects. We demonstrate that NBDHEX, through the simultaneous activation of TRAF2 and JNK, promotes cell death signals, which overcome the anti-apoptotic effects of $\mathrm{p} 38 / \mathrm{p} 21$. A possible practical consequence of these findings is that NBDHEX may reinforce the activity of drugs that recognize members of the TNF receptor superfamily ${ }^{27-29}$ and render the cells more sensitive to the treatment (Fig. 10).

\section{Experimental}

\subsection{Drugs}

NBDHEX was synthesized as previously reported in ref. 7 and dissolved in DMSO. Stock solution aliquots were stored in darkness at room temperature and diluted at the desired 

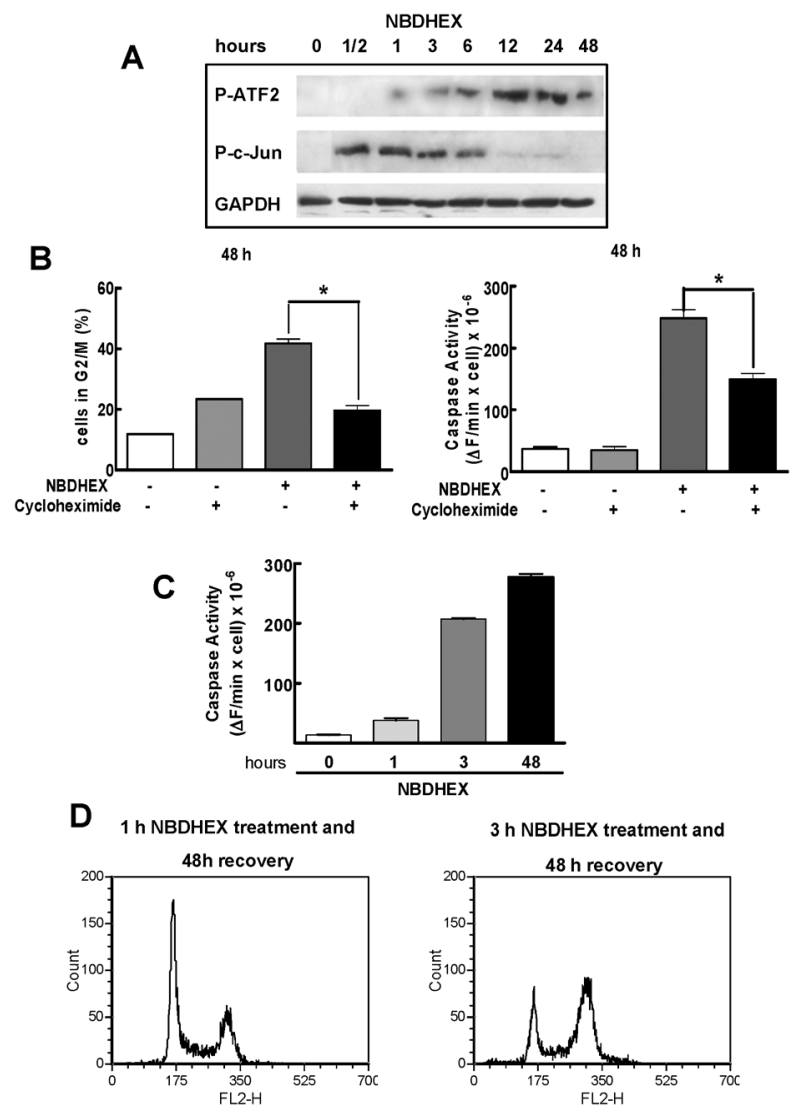

Fig. 8 Cell cycle arrest and apoptosis are transcription-dependent events in U-2OS cells. (A) Time course of the phospho-activation of c-Jun and ATF2 in cells treated with $5 \mu \mathrm{M}$ of NBDHEX. (B) Effect of the protein synthesis inhibitor cycloheximide on the G2/M arrest and the caspase activation caused by 48 hours of NBDHEX-treatment in U-2OS cells. (C) Caspase activity and (D) cell cycle distribution were assessed in U-2OS cells treated with NBDHEX for either 1 or 3 hours and subsequently cultured with a standard drug-free medium for 48 hours. One hour of incubation with NBDHEX is not sufficient to cause $\mathrm{G} 2 / \mathrm{M}$ arrest and apoptosis while 3 hours of incubation cause cell growth arrest and caspase activation at 48 hours, comparable to those observed after 48 hours of continuous exposure to NBDHEX.

concentration in the culture medium immediately before use. The integrity of NBDHEX was verified spectrophotometrically. After dilution, the final DMSO concentration never exceeded $0.01 \%$, a dosage at which DMSO had no cytotoxic effect on our cell lines. The JNK and p38 inhibitors, SP600125 and SB203580, respectively, were purchased from Calbiochem-Novabiochem, Darmstadt, Germany. Cycloheximide, 1,3,7- trimethylxanthine (caffeine) and Z-VAD-fmk were Sigma products.

\subsection{Cell cultures and treatment}

The U-2OS human osteosarcoma cell line was purchased from the American Type Culture Collection (ATCC). The CDDPresistant variant $\mathrm{U}-2 \mathrm{OS} / \mathrm{CDDP} 4 \mu \mathrm{g}$ was established at the Laboratory of Experimental Oncology of the Orthopaedic Rizzoli Institute as previously described. ${ }^{6}$ All cell lines were grown in Iscove's modified Dulbecco's medium supplemented with $10 \%$ FBS, 2 mM L-glutamine, 100 units $\mathrm{mL}^{-1}$ of penicillin, and $100 \mu \mathrm{g} \mathrm{mL}^{-1}$ streptomycin (Sigma Co., St. Louis, MO).
The CDDP-resistant variant was continuously cultured in the presence of the drug concentration used for its selection. All cell lines were maintained at $37{ }^{\circ} \mathrm{C}$ and $5 \% \mathrm{CO}_{2}$ in a humidified atmosphere.

To investigate the process of cell death, U-2OS and U-2OS/ CDDP4 $\mu$ g cell lines were treated with NBDHEX during their logarithmic phase of growth (48-96 hours after seeding). NBDHEX was used at the following concentrations: $5 \mu \mathrm{M}$ in U-2OS cells, 10 and $28 \mu \mathrm{M}$ in the U-2OS/CDDP4 $\mu \mathrm{g}$ cell line. NBDHEX treatment was also performed in the presence of Z-VAD-fmk $(40 \mu \mathrm{M})$, SP600125 $(10 \mu \mathrm{M}$ in U-2OS and $20 \mu \mathrm{M}$ in U-2OS/CDDP4 $\mu \mathrm{g})$, SB203580 $(10 \mu \mathrm{M})$, cycloheximide $(36 \mu \mathrm{M})$, Trolox $(2 \mathrm{mM})$ or caffeine $(2 \mathrm{mM})$, added 1 hour before treatment with NBDHEX. After each treatment, cells were collected at different time points for further analysis.

\subsection{Necrosis/apoptosis determination and cell cycle analysis}

For cell death determination, aliquots of cells were stained with trypan blue and examined by microscopy. Apoptosis was determined by analyzing the nuclear fragmentation, after staining with the DNA-specific dye Hoechst 33342 (Sigma). Apoptosis was also determined by measuring caspase activity as previously reported in ref. 9 and by showing caspase- 9 and -3 cleavage. The percentage of viable, early and late apoptotic, and necrotic cells was determined by simultaneous staining of cells with propidium iodide (PI, $2 \mu \mathrm{g} \mathrm{mL}^{-1}$ ) and Annexin V-FITC $\left(0.5 \mu \mathrm{g} \mathrm{mL}^{-1}\right)$ (Sigma). Stained cells were analyzed by a FACSCalibur flow cytometer (BD Bioscience) as previously reported. ${ }^{30}$ For cell cycle analysis, cells were fixed with $70 \%$ ethanol, stained with propidium iodide, and analyzed by a FACSCalibur instrument. The emission of unstained cells treated with NBDHEX was used as background fluorescence. Flow cytometric data were statistically analyzed by WinMDI version 2.8 software.

\subsection{Qualitative and quantitative proteome analysis by nLC-MS $^{\mathrm{E}}$}

Whole-cell protein extracts digestion and instrument configuration for $\mathrm{nLC}-\mathrm{MS}^{\mathrm{E}}$ experiments were performed as previously described. ${ }^{31}$ Protein extracts of the different conditions from separated experiments were precipitated with a mix of ethanol, methanol and acetone (ratio $2: 1: 1, \mathrm{v} / \mathrm{v}$ ), than dissolved in $50 \mathrm{mM}$ ammonium bicarbonate $\mathrm{pH} 8.5$ containing $1.2 \mathrm{M}$ Urea and $1 \%$ CHAPS and sonicated. Reduction of proteins was obtained by adding DTT $(10 \mathrm{mM})\left(1 \mathrm{~h}\right.$ at $\left.36^{\circ} \mathrm{C}\right)$ and alkylation by adding iodoacetamide $(50 \mathrm{mM})(1 \mathrm{~h}$ at $\mathrm{rt})$. Protein samples were digested with $1: 20(\mathrm{w} / \mathrm{w})$ sequence grade trypsin (Promega) at $36{ }^{\circ} \mathrm{C}$ overnight. Reactions were stopped adding $5 \mu \mathrm{l}$ of $1 \%$ (v/v) TFA. A total of $0.5 \mu \mathrm{g}$ of protein digestion were loaded on the nanoACQUITY UPLC System (Waters Corp., Milford, MA) coupled to a Q-Tof Premier mass spectrometer (Waters Corp., Manchester, UK). Prior loading, a digestion mixture of Enolase (Waters Corp.) from Saccharomyces cerevisiae was added to the sample as internal standard at a final concentration of $100 \mathrm{fmol}$. Samples were injected onto a Symmetry C18 $5 \mu \mathrm{m}, 180 \mu \mathrm{m}$ X $20 \mathrm{~mm}$ precolumn (Waters Corp.) for preconcentration and desalting and subsequently separated using a NanoEase ${ }^{\mathrm{TM}} \mathrm{BEH}$ C18 $1.7 \mu \mathrm{m}, 75 \mu \mathrm{m}$ X 25cm nanoscale LC column (Waters Corp.) 

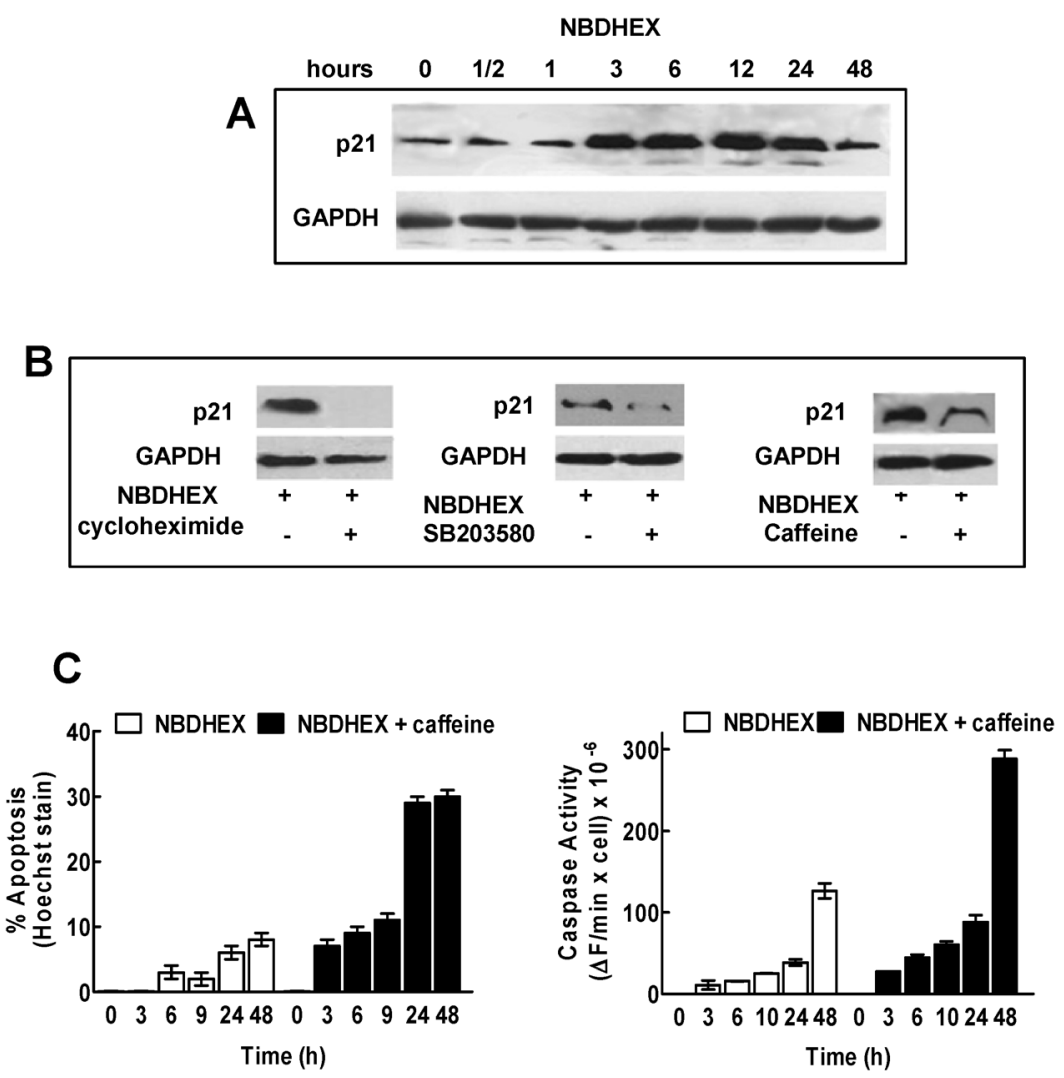

Fig. 9 p21 induces cell cycle arrest. (A) An increase of the basal level of p21 is detectable in U-2OS cells as early as after 3 hours of treatment with $5 \mu \mathrm{M}$ NBDHEX. (B) Cycloheximide $(36 \mu \mathrm{M})$, SB203580 $(10 \mu \mathrm{M})$ and caffeine $(2 \mathrm{mM})$ prevent p21 accumulation in U-2OS cells treated for 24 hours with $5 \mu \mathrm{M}$ NBDHEX. (C) Caffeine $(2 \mathrm{mM})$ causes a strong increase of both apoptotic nuclei and caspase activity with respect to cells treated with only NBDHEX.

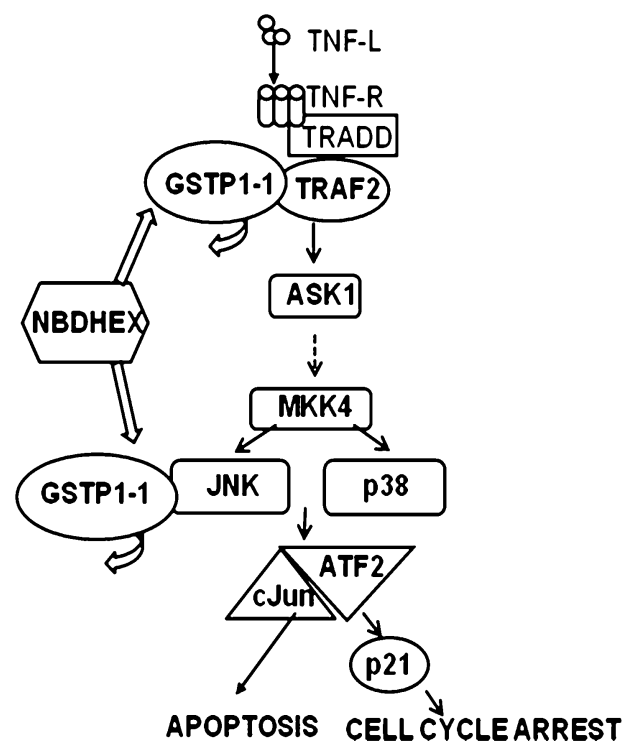

Fig. 10 Proposed action mechanism of NBDHEX in the U-2OS cell line. NBDHEX, through a selective GSTP1-1 targeting, causes the dissociation of both the GSTP1-1:TRAF2 and the GSTP1-1: JNK ${ }^{9}$ complexes and the activation of the MAPK signaling pathway.

maintained at $35{ }^{\circ} \mathrm{C}$. Mobile phase A was water with $0.1 \%$ formic acid, and mobile phase B was $0.1 \%$ formic acid in acetonitrile. Peptides were eluted by a gradient of $3-40 \%$

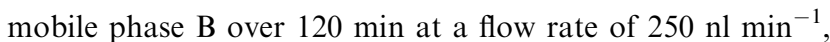
followed by a gradient of $40-90 \%$ mobile phase B over 5 min and a 15 min rinse with $90 \%$ mobile phase B. The Q-Tof Premier mass spectrometer (Waters Corp.) was programmed to step between low $(4 \mathrm{eV})$ and high $(15-40 \mathrm{eV})$ collision energies using a scan time of $1.5 \mathrm{~s}$ over $50-1990 \mathrm{~m} / \mathrm{z}$. Samples of each condition were run at least in triplicate. Continuum LC-MS data were processed and searched using ProteinLynx GlobalServer v2.3 (PLGS, Waters Corporation). Protein identifications were made with the embedded ion accounting algorithm of the software and searching a SWISSProt human database (indexed on September 2008, 25.245 entries) to which sequence from Enolase Saccharomyces cerevisiae was appended. Parameters for database search were: $15 \mathrm{ppm}$ of tolerance for precursor ions, $20 \mathrm{ppm}$ of tolerance for product ions, minimum 3 fragment ions matched per peptide, minimum 7 fragment ions matched per protein, minimum 2 peptides matched per protein, 1 missed cleavage, carbamidomethylation and oxidation of methionine as modifications. The false positive rate (FPR) of the identification algorithm is typically 3 to $4 \%$ with a randomized database, appended to the original one, which is five times the size of the original utilized database. $^{32}$

Relative quantitative analyses (normalization and statistics) were performed by the "Expression tool" included in PLGS software as already reported in the literature. ${ }^{31,32}$ Identified proteins displayed in the protein table were normalized against 
P00924 entry (Enolase Saccharomyces cerevisiae), while the most reproducible peptides for retention time and intensity deriving from Enolase Saccharomyces cerevisiae digestion $(\mathrm{m} / \mathrm{z}$ 1286.7148, $\mathrm{m} / \mathrm{z}$ 1578.80, $\mathrm{m} / \mathrm{z} 1555.95, \mathrm{~m} / \mathrm{z} 1840.89, \mathrm{~m} / \mathrm{z}$ 2441.10) were used to normalize the EMRTs table, the list of paired peptide exact masses and retention time. The list of normalized proteins were screened according to the following criteria: proteins identified in at least 2 out of 3 injections of the same condition; proteins with $0<P<0.05$ or $0.95<$ $P<1$ and proteins with a ratio of expression level within the conditions above 1.5 on the decimal scale. If $0<P<0.05$ the likelihood of down-regulation is greater than $95 \%$, if $0.95<$ $P<1$ the likelihood of up-regulation is greater than $95 \%$. Setting the threshold of the ratio at 1.5 on a decimal scale allowed us to consider average relative fold change \pm 0.50 on a natural log scale. This setting is more stringent than \pm 0.30 on a natural $\log$ scale which is typically $2-3$ times higher than the estimated error on the intensity measurements. ${ }^{32}$

\subsection{Ingenuity pathway analysis (IPA)}

The modulated proteins, identified by shotgun proteomic analysis, were further analysed by Ingenuity Pathway Analysis (IPA v.7.0; Ingenuity Systems, Mountain View, CA). This software constructs protein interaction networks or pathways starting from a database of known protein-protein interactions based on direct (physical) or indirect (transcriptional and translational regulation, post-translational modifications, etc.) evidence. The two resulting networks obtained by our dataset were merged and the significance in Functional Analysis for the main nodes was then evaluated considering the calculated $p$-value. $P$-values identify statistically significant over-representation of functional analysis molecules in a given process. $P$-values less than 0.05 indicate a statistically significant, non-random association.

\subsection{Immunoprecipitation}

The immunoprecipitation was carried out as previously described. ${ }^{9}$ To summarize, $400 \mu \mathrm{g}$ of protein from total cell lysates were incubated overnight at $4{ }^{\circ} \mathrm{C}$ in lysis buffer with $6 \mu \mathrm{L}$ of the polyclonal anti-GSTP1-1 antibody (Cell Signaling) to a total volume of $400 \mu \mathrm{L}$. Immunocomplexes were adsorbed with $20 \mu \mathrm{L}$ of protein A-Sepharose for 2 hours at $4{ }^{\circ} \mathrm{C}$. Immune pellets (IP) were boiled in the SDS sample buffer. IP $(7 \mu \mathrm{g})$ and supernatant $(30 \mu \mathrm{g})$ proteins were loaded on a $12 \%$ SDS-polyacrylamide gel and transferred to a nitrocellulose membrane. The polyclonal anti-TRAF2 antibody (1:1000; Cell Signaling), the monoclonal anti-GSTP1-1 (1: 5000; Cell Signaling) and anti-GAPDH (1:3000; Santa Cruz) antibodies were used as primary antibodies and recognized by the "SuperSignal" substrate chemiluminescence reagent.

\subsection{Western blotting}

Cell pellets were washed in PBS and re-suspended in a lysis buffer containing $50 \mathrm{mM}$ Tris- $\mathrm{HCl}$ ( $\mathrm{pH} 7.4), 1 \mathrm{mM}$ EDTA, $1 \mathrm{mM}$ EGTA, $1 \%$ Triton $\mathrm{X}-100$ and a protease inhibitor cocktail. Proteins were loaded on a $12 \%$ SDS-polyacrylamide gel and transferred onto a nitrocellulose membrane (Biorad). The primary antibodies used were: monoclonal anti-phospho
$\operatorname{Thr}^{183} \operatorname{Tyr}^{185}$ JNK $(1: 1000$, Santa Cruz), polyclonal antiSAPK/JNK (1:2000, Cell Signaling), anti-p38 MAPK (1:2000, Cell Signaling), anti-phospho $\operatorname{Ser}^{63}$ c-Jun (1:1000, Cell Signaling), polyclonal anti-phospho $\mathrm{Thr}^{71}$ ATF2 (1: 1000, Cell Signaling), polyclonal anti-phospho $\mathrm{Thr}^{261}$ MKK4 (1:1000, Cell Signaling), monoclonal anti-phospho $\mathrm{Thr}^{180}$ $\operatorname{Tyr}^{182}$ p38 (1:1000, Cell Signaling), monoclonal anti-p21 ( $1: 2000$, Cell Signaling), polyclonal anti-caspase-9 and anticaspase-3 (1:1000, Cell Signaling) and monoclonal antiGAPDH (1:3000; Santa Cruz). Anti-rabbit and anti-mouse (Cell Signaling) were used as secondary antibodies at the appropriate dilutions.

\subsection{Data presentation}

All of the experiments were repeated at least three times; results are presented as mean \pm SD. Statistical evaluation was executed using the Student's $t$ test. The criterion for statistical significance used was $P<0.05$.

\section{Acknowledgements}

Financial support: (a,e) Associazione Italiana per la Ricerca sul Cancro (A.I.R.C.); Italian Ministry of Health "Alleanza contro il Cancro" project; (e) EuroBoNeT, a European Commissiongranted Network of Excellence for studying the pathology and genetics of bone tumours (LSHC-CT-2006-018814); (a) Filas project "Identificazione di principi attivi per patologie tumorali cardiovascolari e infettive".

Conflict of interest: The authors do not have any conflicts of interest to report for this manuscript.

\section{References}

1 D. L. Eaton and T. K. Bammler, Toxicol. Sci., 1999, 49, 156-164.

2 V. Adler, Z. Yin, S. Y. Fuchs, M. Benezra, L. Rosario, K. D. Tew, M. R. Pincus, M. Sardana, C. J. Henderson, C. R. Wolf, R. J. Davis and Z. Ronai, EMBO J., 1999, 18, 1321-1334.

3 Y. Wu, Y. Fan, B. Xue, L. Luo, J. Shen, S. Zhang, Y. Jiang and Z. Yin, Oncogene, 2006, 25, 5787-5800.

4 R. M. Locksley, N. Killeen and M. J. Lenardo, Cell, 2001, 104, 487-501.

5 H. Ichijo, E. Nishida, K. Irie, P. ten Dijke, M. Saitoh, T. Moriguchi, M. Takagi, K. Matsumoto, K. Miyazono and Y. Gotoh, Science, 1997, 275, 90-94.

6 M. Pasello, F. Michelacci, I. Scionti, C. M. Hattinger, M. Zuntini, A. M. Caccuri, K. Scotlandi, P. Picci and M. Serra, Cancer Res., 2008, 68, 6661-6668.

7 G. Ricci, F. De Maria, G. Antonini, P. Turella, A. Bullo, L. Stella, G. Filomeni, G. Federici and A. M. Caccuri, J. Biol. Chem., 2005, 280, 26397-26405.

8 L. Federici, C. Lo Sterzo, S. Pezzola, A. Di Matteo, F. Scaloni, G. Federici and A. M. Caccuri, Cancer Res., 2009, 69, 8025-8034.

9 P. Turella, C. Cerella, G. Filomeni, A. Bullo, F. De Maria, L. Ghibelli, M. R. Ciriolo, M. Cianfriglia, M. Mattei, G. Federici, G. Ricci and A. M. Caccuri, Cancer Res., 2005, 65, 3751-3761.

10 G. Filomeni, P. Turella, M. L. Dupuis, O. Forini, M. R. Ciriolo, M. Cianfriglia, S. Pezzola, G. Federici and A. M. Caccuri, Mol. Cancer Ther., 2008, 7, 371-379.

11 A. Ascione, M. Cianfriglia, M. L. Dupuis, A. Mallano, A. Sau, F. Pellizzari Tregno, S. Pezzola and A. M. Caccuri, Cancer Chemother. Pharmacol., 2009, 64, 419-424.

12 F. Pellizzari Tregno, A. Sau, S. Pezzola, C. Geroni, C. Lapenta, M. Spada, G. Filomeni, E. Bonanno, G. Federici and A. M. Caccuri, Eur. J. Cancer, 2009, 45, 2606-2617. 
13 L. Tentori, A. S. Dorio, E. Mazzon, A. Muzi, A. Sau, S. Cuzzocrea, P. Vernole, G. Federici, A. M. Caccuri and G. Graziani, Eur. J. Cancer, 2011, 47, 1219-1230.

14 K. Scotlandi, D. Remondini, G. Castellani, M. C. Manara, F. Nardi, L. Cantiani, M. Francesconi, M. Mercuri, A. M Caccuri, M. Serra, S. Knuutila and P. Picci, J. Clin. Oncol., 2009, 27, 2209-2216.

15 H. C. Reinhardt, A. S. Aslanian, J. A. Lees and M. B. Yaffe, Cancer Cell, 2007, 11, 175-189.

16 T. M. Thornton and M. Rincon, Int. J. Biol. Sci., 2009, 5, 44-51.

17 L. Ling and D. V. Goeddel, J. Biol. Chem., 2000, 275(31), 23852-23860.

18 T. Bouwmeester, A. Bauch, H. Ruffner, P. O. Angrand, G. Bergamini, K. Croughton, C. Cruciat, D. Eberhard, J. Gagneur, S. Ghidelli, C. Hopf, B. Huhse, R. Mangano, A. M. Michon, M. Schirle, J. Schlegl, M. Schwab, M. A. Stein, A. Bauer, G. Casari, G. Drewes, A. C. Gavin, D. B. Jackson, G. Joberty, G. Neubauer, J. Rick, B. Kuster and G. Superti-Furga, Nat. Cell Biol., 2004, 6(2), 97-105; Erratum in: Nat. Cell Biol., 2004, 6(5), 465.

19 H. Chen, Y. Wu, Y. Zhang, L. Jin, L. Luo, B. Xue, C. Lu, X. Zhang and Z. Yin, FEBS Lett., 2006, 580(13), 3145-3152.

20 R. M. Ewing, P. Chu, F. Elisma, H. Li, P. Taylor, S. Climie, L. McBroom-Cerajewski, M. D. Robinson, L. O'Connor, M. Li, R. Taylor, M. Dharsee, Y. Ho, A. Heilbut, L. Moore, S. Zhang, O. Ornatsky, Y. V. Bukhman, M. Ethier, Y. Sheng, J. Vasilescu, M. Abu-Farha, J. P. Lambert, H. S. Duewel, I. I. Stewart, B. Kuehl, K. Hogue, K. Colwill, K. Gladwish, B. Muskat,
R. Kinach, S. L. Adams, M. F. Moran, G. B. Morin, T. Topaloglou and D. Figeys, Mol. Syst. Biol., 2007, 3, 89.

21 S. Dai, L. Jiang, G. Wang, X. Zhou, X. Wei, H. Cheng, Z. Wu and D. Wei, J. Cell. Mol. Med., 2010, 14(3), 710-725.

22 J. Wendt, S. Radetzki, C. von Haefen, P. G. Hemmati, D. Güner, K. Schulze-Osthoff, B. Dörken and P. T. Daniel, Oncogene, 2005, 25, 972-980.

23 A. Rallis, C. Moore and J. Ng, Dev. Biol., 2010, 339, 65-77.

24 J. J. Ventura, A. Hübner, C. Zhang, R. A. Flavell, K. M. Shokat and R. J. Davis, Mol. Cell, 2006, 21, 701-710.

25 M. Lauricella, G. Calvaruso, M. Carabillò, A. D’Anneo, M. Giuliano, S. Emanuele, R. Vento and G. Tesoriere, FEBS Lett., 2001, 499, 191-197.

26 B. Liu and K. Shuai, J. Biol. Chem., 2001, 276, 36624-36631.

27 V. Baud, Z. G. Liu, B. Bennett, N. Suzuki, Y. Xia and M. Karin, Genes Dev., 1999, 13, 1297-1308.

28 J. Fellenberg, H. Mau, C. Scheuerpflug, V. Ewerbeck and K. M. Debatin, Int. J. Cancer, 1997, 72, 536-542.

29 R. M. Locklin, E. Federici, B. Espina, P. A. Hulley, R. G. Russell and C. M. Edwards, Mol. Cancer Ther., 2007, 6, 3219-3228.

30 I. Vermes, C. Haanen, H. Steffens-Nakken and C. Reutelingsperger, J. Immunol. Methods, 1995, 184, 39-51.

31 S. D'Aguanno, A. D'Alessandro, L. Pieroni, A. Roveri, M. Zaccarin, V. Marzano, M. De Canio, S. Bernardini, G. Federici and A. Urbani, J. Proteome Res., 2011, 10, 416-428.

32 J. P. Vissers, J. I. Langridge and J. M. Aerts, Mol. Cell. Proteomics, 2007, 6, 755-766 